\title{
The Economic and Psychosocial Comorbidity Burden Among Adults with Moderate-to-Severe Atopic Dermatitis in Europe: Analysis of a Cross-Sectional Survey
}

\author{
Giampiero Girolomoni • Thomas Luger • Audrey Nosbaum • \\ David Gruben • William Romero • Lyndon John Llamado • \\ Marco DiBonaventura (D)
}

Received: July 14, 2020 / Published online: November 12, 2020

(C) The Author(s) 2020

\section{ABSTRACT}

Introduction: Atopic dermatitis (AD) is a common inflammatory disease of the skin, which may have a substantial impact on patients' health-related quality of life (HRQoL). The aim of this study was to quantify the economic burden (direct and indirect costs) of moderateto-severe $\mathrm{AD}$ and evaluate the prevalence and impact of psychosocial comorbidities among patients in the European Union-5 (France, Germany, Italy, Spain, and the UK).

G. Girolomoni

Department of Medicine, Università di Verona,

Verona, Italy

T. Luger

Department of Dermatology, University of Münster, Münster, Germany

A. Nosbaum

Department of Clinical Immunology and Allergy,

Lyon-Sud University Hospital, Pierre-Bénite, France

D. Gruben

Pfizer Inc., Groton, CT, USA

W. Romero

Pfizer Ltd., Tadworth, Surrey, UK

L. J. Llamado

Pfizer Inc., Makati, Philippines

M. DiBonaventura $(\square)$

Pfizer Inc., New York, NY, USA

e-mail: marco.dibonaventura@pfizer.com
Methods: Data were analyzed from the 2017 EU5 National Health and Wellness Survey. Respondents with a physician diagnosis of $\mathrm{AD} /$ eczema who were considered to have moderateto-severe $\mathrm{AD}$ based on a Dermatology Life Quality Index (DLQI) score $\geq 6$ were included. Direct costs, indirect costs, and psychosocial comorbidities (sleep difficulties and anxiety based on self-report, depression based on the Patient Health Questionnaire-9) were reported descriptively. Generalized linear models were used to examine the relationship between psychosocial comorbidities and health outcomes (the Short Form-36 version 2 [SF-36v2], EuroQoL 5-dimension 5-level, Work Productivity and Activity Impairment questionnaire, and healthcare resource utilization).

Results: Overall, 1014 patients were included in the analysis. Total annual direct costs ranged from $€ 2242$ to $€ 6924$ and total annual indirect costs ranged from $€ 7277$ to $€ 14,236$, depending on the level of disease severity. Sleep difficulties, anxiety, and depression were reported by $61.6 \%, 52.7 \%$, and $75.8 \%$ of patients, respectively. These comorbidities were significantly associated with reduced physical and mental component summary scores from SF-36v2 and increased overall work impairment $(p<0.05$ for all).

Conclusions: A significant economic burden was observed for patients with moderate-tosevere AD. Sleep difficulties, depression, and anxiety were observed in more than half of 
moderate-to-severe $\mathrm{AD}$ patients and were significantly associated with decrements in HRQoL and with work-related impairment. Reducing the burden of these psychosocial comorbidities in $\mathrm{AD}$ could have significant benefit to patients and society.

Keywords: Anxiety; Atopic dermatitis; Depression; Health-related quality of life; Healthcare resource utilization; Sleep difficulties; Work impairment

\section{Key Summary Points}

\section{Why carry out this study?}

Atopic dermatitis (AD) is associated with a significant direct and indirect economic burden, and comorbidities associated with the disease can lead to poor health status, health-related quality of life (HRQoL), and work productivity.

Data on the overall costs, prevalence, and impact of psychosocial comorbidities of $\mathrm{AD}$ among European patients are limited.

This analysis quantified the economic impact (direct and indirect costs) and evaluated the prevalence and impact of psychosocial comorbidities (sleep difficulties, anxiety, and depression) in adult patients with moderate-to-severe AD in the European Union-5 (EU5) using data from the 2017 National Health and Wellness Survey.

\section{What was learned from the study?}

Moderate-to-severe $\mathrm{AD}$ resulted in significant indirect (up to $€ 14,000$ per patient per year) and direct (up to $€ 7000$ per patient per year) costs across the EU5.

Sleep difficulties, depression, and anxiety were observed in more than half of patients with moderate-to-severe $\mathrm{AD}$ and were significantly associated with decrements in HRQoL and work-related impairment.

\section{DIGITAL FEATURES}

This article is published with digital features to facilitate understanding of the article. To view digital features for this article go to https://doi. org/10.6084/m9.figshare.12902486.

\section{INTRODUCTION}

Atopic dermatitis (AD) is a common, chronic, and relapsing inflammatory disease that is characterized by intense itch (pruritus) and dry skin [1]. Affecting up to $20 \%$ of the population [2], $\mathrm{AD}$ has been found to have a substantial impact on health-related quality of life (HRQoL), particularly among patients with more severe disease $[3,4]$.

There is also a significant economic burden of $\mathrm{AD}$ in terms of direct medical costs (i.e., direct costs) and costs through lost work productivity (i.e., indirect costs). Several studies in the US that leveraged administrative claims databases have reported that direct annual costs range from $\$ 15,000$ to $\$ 20,000$ per patient for those with moderate-to-severe disease, with the largest share of costs attributed to outpatient visits $[5,6]$. Data from European patients are limited; however, a Spanish registry study found that direct costs ranged from $€ 2000$ to $€ 3500$ per patient per year for patients with moderate-to-severe AD [7]. A study in The Netherlands found that patients with uncontrolled disease who were eligible for systemic therapy had annual per patient direct and indirect costs of $€ 6993$ and $€ 13,702$, respectively [8].

Itch can be particularly disruptive to sleep in patients with AD [9]. Sleep disruption, especially when combined with the social stigmatization of visible skin lesions, can lead to increased rates of depression, anxiety, and suicidality among patients with AD [10-12]. Data from the National Health and Nutrition Examination Survey indicated that patients with AD had nearly twice the odds of having depression relative to patients without $\mathrm{AD}$ and more than two- and five-times greater odds of having moderate and severe depression, respectively, relative to patients without $\mathrm{AD}$ [10]. 
The objectives of this study were to determine the economic burden (both direct and indirect costs) associated with moderate-to-severe AD in the European Union-5 (EU5; France, Germany, Italy, Spain, and the UK) and to estimate the prevalence of common psychosocial comorbidities (sleep difficulties, anxiety, and depression) among patients with moderateto-severe $\mathrm{AD}$. The presence and severity of these comorbidities were associated with a wide array of health outcomes, including HRQOL, work and activity impairment, and healthcare resource utilization. Collectively, these data can be used to better understand the impact that moderate-to-severe $\mathrm{AD}$ has on European patients, healthcare systems, and overall society to improve its management.

\section{METHODS}

\section{Data Source}

This study involves an analysis of the crosssectional 2017 National Health and Wellness Survey (NHWS), an annual, cross-sectional, internet-based survey of adults ( $\geq 18$ years) conducted across several countries. The protocol and study materials associated with the original fielding of the 2017 NHWS were reviewed by the Pearl Institutional Review Board (Indianapolis, IN, USA) and granted exemption status. The current study used the EU5 dataset $(N=62,000$; France $[n=15,000]$, Germany $[n=15,000]$, Italy $[n=10,000]$, Spain $[n=7000]$, and UK $[n=15,000])$. Potential respondents to the NHWS were recruited through various online panels (e.g., Lightspeed Research) and were sampled in a random stratified manner to mimic the demographic distributions of each country's adult population based on the International Database of the United States Census [13].

Potential respondents received an email invitation to complete the survey. Respondents who provided informed consent electronically completed the survey, which took approximately 30-45 min. Respondents who completed the survey were compensated with points valued between $\$ 5$ and $\$ 10$ USD.

\section{Sample}

Respondents who completed the NHWS were included in the analyses if they self-reported a physician diagnosis of "atopic dermatitis" or "eczema" and scored $\geq 6$ on the Dermatology Life Quality Index (DLQI), which suggested a "moderate" to "extremely large" effect on a patient's quality of life [14].

\section{Measures}

\section{Demographics and Health History}

Respondents answered several demographic questions, including country, age, sex, marital status, income, and employment status; they also reported general health history information, including height and weight used to calculate a body mass index category, comorbidities used to calculate a Charlson comorbidity index (CCI) [15], and the number of years diagnosed with $\mathrm{AD}$.

\section{Psychosocial Comorbidities}

Respondents self-reported whether they experienced either "insomnia" or "sleep difficulties" in the past 12 months and reported the level of severity for each as "mild," "moderate," or "severe." A severity of sleep difficulties variable was defined as the highest self-reported severity rating of either insomnia or sleep difficulties in the past 12 months (mild, moderate, or severe) with an extra category of "no sleep difficulties" reserved for respondents who did not report either condition. Respondents also self-reported whether they had experienced anxiety in the past 12 months. Finally, respondents completed the Patient Health Questionnaire-9 (PHQ-9) [16], a validated nine-item instrument used to assess the severity of depression (0-4, "none/ minimal depression"; 5-9, "mild depression"; 10-14, "moderate depression"; 15-19, "moderately severe depression"; 20-27, "severe depression") in the past 2 weeks.

\section{Health Outcomes}

The Short Form-36 version 2 (SF-36v2) [17], EuroQoL 5-dimension 5-level questionnaire (EQ-5D-5L) [18], and the Work Productivity and 
Activity Impairment questionnaire-General Health version (WPAI-GH) [19] were all administered as part of the NHWS. The physical component summary (PCS) and mental component summary (MCS) scores from SF-36v2, which assess aspects of generic health status, were included in the study. The PCS and MCS scores are normalized, with the population mean and standard deviation set to 50 and 10 , respectively; higher scores indicate better health status [17]. The EQ-5D-5L is a generic HRQoL measure that produces a health utility index score from 0 to 1 , with higher scores indicating better HRQoL [18]. The WPAI-GH is a six-item validated tool to assess the impact of health on work and leisure activities. It includes four metrics: absenteeism (percentage of work time missed because of one's health in the past 7 days), presenteeism (percentage impairment experienced while at work in the past 7 days because of one's health), overall work impairment (combination of absenteeism and presenteeism), and activity impairment (percentage impairment in daily activities because of one's health in the past 7 days) [19]. Respondents also self-reported healthcare resource utilization (number of healthcare provider visits, emergency room visits, and hospitalizations) in the past 6 months.

\section{Statistical Analyses}

Demographic, health characteristics, and health outcome variables were reported descriptively using frequencies and percentages for categorical variables and means and standard deviations for continuous variables. The economic burden from indirect costs was calculated using a human capital approach; the proportion of work time that was missed was multiplied by the average annual wage to arrive at the cost for the lost productivity. Specifically, the mean percentage of overall work impairment observed within each country and DLQI severity band was multiplied by the country-specific median annual wage rates in 2017 (the same year as the NHWS data collection) from Eurostat [20]. Due to small sample sizes at the country level in some cases, a combined EU5 calculation was performed and reported. Direct costs were calculated by multiplying the number of healthcare resource use visits by two (to annualize them) and then by the unit costs for these events within each country (e.g., if there was a mean of 5 physician visits in the prior 6 months and the average physician visit cost was $€ 50$, then the total annual cost would be $€ 500$ ). Unit costs were inflation adjusted to 2017 costs using the harmonized indices of consumer prices from Eurostat [21-23]. Total direct costs were calculated as the sum of the costs of physician visits, emergency room visits, and hospitalizations, which were reported overall at the EU5 level and by individual countries.

The prevalence of psychosocial comorbidities among respondents with $\mathrm{AD}$ was reported descriptively using frequencies and percentages. Generalized linear models were used to examine the association between psychosocial comorbidity categories and each health outcome variable. For normally distributed outcomes (SF$36 \mathrm{v} 2$ component summary scores and EQ-5D5L index scores), a normal distribution with an identity link function was used. For positively skewed variables (WPAI-GH scores and healthcare resource utilization), negative binomial distributions with a log-link function were used. All models controlled for age, sex, country, income, employment status, body mass index, CCI score, and presence of other atopic conditions. Adjusted means were reported (on the original metric of each variable) for each level of the comorbidity category. The reference category was set to be the lowest level of each psychosocial comorbidity. Statistical significance was based on $p<0.05$ relative to this reference category.

\section{RESULTS}

\section{Sample Characteristics and Prevalence of Psychosocial Comorbidities}

A total of 1014 respondents in the EU5 met criteria for having moderate-to-severe $\mathrm{AD}$ and were included in the analyses. Demographic and health history differences across the DLQI severity bands (i.e., "moderate," "very large," or 
"extremely large" effect on the patient's quality of life) are reported in Table 1 . The mean age of patients ranged from 39.7 to 42.3 years; patients were predominantly female (53.6-72.0\%), with more than a third having been diagnosed with $\mathrm{AD}$ for $\geq 16$ years (31.9-37.2\%). The proportion of male patients increased with severity $(p<0.05)$ and a greater comorbidity burden, as measured by the CCI, also increased with severity $(p<0.05)$. No other differences were observed.

\section{Overall Economic Burden}

Overall work productivity and annualized healthcare resource use by country are presented in Table 2 . Rates of overall work impairment ranged from $32.3 \%$ (UK) to $47.3 \%$ (Spain) among patients in the moderate DLQI severity band, from $33.2 \%$ (UK) to 58.9\% (Spain) among patients in the very large effect DLQI severity band, and from $67.9 \%$ (UK) to $74.0 \%$ (Italy) in the extremely large DLQI severity band. Applying published country-specific median wage data to these overall work impairment figures, the total indirect costs for moderate-to-severe patients across the EU5 ranged from $€ 7277$ to $€ 14,236$, depending on the DLQI severity band (see Fig. 1). Individual country results were limited by small sample sizes, yet were as follows: France, €6490-€13,315; Germany, $€ 8655-€ 13,813$; Italy, €6824-€11,885; Spain, $€ 7012-€ 10,681$; and UK, €7685-€16,150.

With respect to direct healthcare costs, the number of emergency room visits and hospitalizations (except for hospitalizations in France) increased significantly along with severity (Table 2). Although there were numerical differences in healthcare provider visits across DLQI severity bands, these were not statistically significant (Table 2). Applying country-specific unit costs, the annualized perpatient direct costs across the EU5 ranged from $€ 2242$ (moderate DLQI severity band) to $€ 6924$ (extremely large DLQI severity band) (Fig. 1). Country-specific results were as follows: France, $€ 2764-€ 6261 ;$ Germany, €3028-€9894; Italy, $€ 885-€ 4304$; Spain, €720-€4706 (Spain had a different pattern of direct costs across DLQI bands compared with the EU5; the extremely large DLQI severity band had the lowest costs and the very large DLQI severity band had the highest costs); UK, €2397-€7055.

\section{Prevalence and Impact of Psychosocial Comorbidities}

Psychosocial comorbidities were common across the EU5 countries (Table 3). A total of $61.7 \%$ of patients reported some form of sleep difficulties $(37.8 \%$ reported "moderate" or "severe" difficulties), $52.7 \%$ reported anxiety, and $75.9 \%$ reported some form of depression (23.8\% reported "moderately severe" or "severe" depression). The patterns were largely similar across countries, with the exception of patients in Germany, who reported lower levels of anxiety $(29.5 \%)$ compared with other countries (51.3\% to $61.5 \%)$.

The presence and increasing severity of these psychosocial comorbidities was significantly associated with poorer health outcomes, even after adjusting for confounding factors (Table 4). Patients with moderate or severe sleep difficulties reported significantly worse MCS (36.4 and 33.1, respectively, vs. 42.9 for those without sleep difficulties) and PCS (40.0 and 40.6 vs. 42.9$)$ and EQ-5D health utilities (0.52 and 0.46 vs. 0.66 ) compared with those without sleep difficulties (all $p<0.05$ ). Similarly, patients with moderate or severe sleep difficulties reported significantly greater overall work impairment $(61.7 \%$ and $69.7 \%$, respectively, vs. $52.3 \%$ for those without sleep difficulties), greater activity impairment $(63.6 \%$ and $65.1 \%$ vs. $47.7 \%)$, and more physician visits (12.2 and 14.3 vs. 9.2) (all $p<0.05$ ). No differences were observed with respect to hospitalizations, and only patients with severe sleep difficulties reported significantly more emergency room visits compared with patients without sleep difficulties (1.05 vs. 0.63, $p<0.05)$. Patients with mild sleep difficulties were typically not statistically different from those without sleep difficulties across most health outcomes, with the exception of MCS and activity impairment.

Patients with anxiety reported significantly worse MCS (36.6 vs. 43.7) and EQ-5D health 
Table 1 Demographics and baseline characteristics of patients with atopic dermatitis by Dermatology Life Quality Index severity bands

\begin{tabular}{|c|c|c|c|c|}
\hline & $\begin{array}{l}\text { Moderate effect } \\
\text { (DLQI 6-10) } \\
(N=597)\end{array}$ & $\begin{array}{l}\text { Very large effect } \\
\text { (DLQI 11-20) } \\
(N=348)\end{array}$ & $\begin{array}{l}\text { Extremely large effect } \\
\text { (DLQI 21-30) } \\
(N=69)\end{array}$ & $p$ value \\
\hline Age, mean (SD) & $42.3(16.3)$ & $40.3(14.2)$ & $39.7(13.5)$ & $<0.0001$ \\
\hline Female $[n(\%)]$ & $430(72.0)$ & $235(67.5)$ & $37(53.6)$ & $<0.0001$ \\
\hline \multicolumn{5}{|l|}{ Country $[n(\%)]$} \\
\hline France & $157(26.3)$ & $82(23.6)$ & $17(24.6)$ & \multirow{5}{*}{$<0.0001$} \\
\hline Germany & $98(16.4)$ & $68(19.5)$ & $17(24.6)$ & \\
\hline UK & $177(29.7)$ & $83(23.9)$ & $23(33.3)$ & \\
\hline Italy & $87(14.6)$ & $64(18.4)$ & $9(13.0)$ & \\
\hline Spain & $78(13.1)$ & $51(14.7)$ & $3(4.4)$ & \\
\hline Married/living with partner $[n(\%)]$ & $335(56.1)$ & $193(55.5)$ & $49(71.0)$ & 0.0432 \\
\hline University educated $[n(\%)]$ & $276(46.2)$ & $168(48.3)$ & $37(53.6)$ & 0.0845 \\
\hline Currently employed $[n(\%)]$ & $341(57.1)$ & $217(62.4)$ & $49(71.0)$ & 0.0008 \\
\hline \multicolumn{5}{|l|}{ Body mass index $[n(\%)]$} \\
\hline$<18.5$ (underweight) & $43(7.2)$ & $16(4.6)$ & $6(8.7)$ & \multirow{5}{*}{$<0.0001$} \\
\hline 18.5 to $<25$ (normal weight) & $238(39.9)$ & $146(42.0)$ & $23(33.3)$ & \\
\hline 25 to $<30$ (overweight) & $145(24.3)$ & $91(26.2)$ & $14(20.3)$ & \\
\hline$\geq 30$ (obese) & $126(21.1)$ & $79(22.7)$ & $24(34.8)$ & \\
\hline Missing/unknown & $45(7.5)$ & $16(4.6)$ & $2(2.9)$ & \\
\hline \multicolumn{5}{|l|}{ Smoking status $[n(\%)]$} \\
\hline Currently smoke & $189(31.7)$ & $110(31.6)$ & $30(43.5)$ & \multirow{3}{*}{$<0.0001$} \\
\hline Former smoker & $146(24.5)$ & $89(25.6)$ & $14(20.3)$ & \\
\hline Never smoked & $262(43.9)$ & $149(42.8)$ & $25(36.2)$ & \\
\hline \multicolumn{5}{|l|}{ Alcohol consumption $[n(\%)]$} \\
\hline Currently drink & $470(78.7)$ & $258(74.1)$ & $51(73.9)$ & \multirow{2}{*}{0.1979} \\
\hline Do not currently drink & $127(21.3)$ & $90(25.9)$ & $18(26.1)$ & \\
\hline \multicolumn{5}{|l|}{ Charlson comorbidity index $[n(\%)]$} \\
\hline 0 & $470(78.7)$ & $275(79.0)$ & $39(56.5)$ & \multirow{4}{*}{$<0.0001$} \\
\hline 1 & $69(11.6)$ & $35(10.1)$ & $18(26.1)$ & \\
\hline 2 & $32(5.4)$ & $20(5.8)$ & $4(5.8)$ & \\
\hline$\geq 3$ & $26(4.4)$ & $18(5.2)$ & $8(11.6)$ & \\
\hline
\end{tabular}


Table 1 continued

$\begin{array}{llll}\text { Moderate effect } & \text { Very large effect } & \text { Extremely large effect } & p \text { value } \\ (\text { DLQI 6-10) } & (\text { DLQI 11-20) } & (\text { DLQI 21-30) } & \\ (N=597) & (N=348) & (N=69) & \end{array}$

Other atopic condition $[n(\%)]$

\begin{tabular}{lcccc}
$\begin{array}{l}\text { Allergic rhinitis and/or asthma } \\
\text { Neither allergic rhinitis nor asthma }\end{array}$ & $234(39.2)$ & $148(42.5)$ & $35(50.7)$ & 0.0057 \\
$\begin{array}{l}\text { Years since diagnosis of atopic dermatitis } \\
<5 \text { years }\end{array}$ & $200(57.5)$ & $34(49.3)$ & \\
6-10 years & $197(33.0)$ & $142(40.8)$ & $19(27.5)$ & \\
$11-15$ years & $89(14.9)$ & $50(14.4)$ & $13(18.8)$ & $<0.0001$ \\
$\geq 16$ years & $63(10.6)$ & $22(6.3)$ & $8(11.6)$ & \\
Missing/unknown & $222(37.2)$ & $111(31.9)$ & $25(36.2)$ & \\
\hline
\end{tabular}

DLQI Dermatology Life Quality Index

utilities (0.66 vs. 0.76) and higher levels of absenteeism (17.4\% vs. $12.5 \%)$, presenteeism $(42.5 \%$ vs. $35.1 \%)$, overall work impairment (49.3\% vs. $39.9 \%)$, and activity impairment ( $49.8 \%$ vs. $41.6 \%)$ compared with patients who did not report anxiety (all $p<0.05$ ). Although patients with anxiety also had a trend toward more healthcare resource use visits in the past 6 months, only the number of physician visits was significantly different (9.7 vs. 6.7, $p<0.05$ ).

Patients with an increasing severity of depression (particularly moderate, moderately severe, and severe levels) exhibited significantly poorer outcomes with respect to MCS, PCS, EQ$5 \mathrm{D}$ health utilities, and all WPAI-GH metrics compared with patients without depression (Table 4). A similar pattern was observed for physician visits (all $p<0.05$ ), although the number of emergency room visits was only significantly different between patients without depression and those with moderate depression (0.89 vs. $0.55, p<0.05)$ and the number of hospitalizations was only significantly different between patients without depression and those with moderate $(0.58$ vs. $0.30, p<0.05)$ and moderately severe depression $(0.53$ vs. 0.30 , $p<0.05)$.

\section{DISCUSSION}

The results of this study suggest a significant economic burden for patients with moderateto-severe $\mathrm{AD}$ across the EU5. Direct costs for patients with the highest $\mathrm{AD}$ severities can approach $€ 7000$ per patient per year. However, the indirect costs are notably higher (ranging from $€ 7000$ to $€ 14,000$ ) per patient per year and reflect the impact of the disease, its symptoms, and the sequelae that can affect patients' ability to be present and productive at work. Comparisons with the literature are difficult given the lack of data, but our direct-cost findings in patients in Spain are similar to those reported previously [7]. Furthermore, the results across the EU5 for both direct and indirect costs are similar to those reported in The Netherlands [8]. The results of this study are also similar to a cross-sectional study in Japan, which found that cost per adult patient with AD increased with disease severity [24]. These findings reaffirm the impact that $\mathrm{AD}$, particularly moderate-to-severe $\mathrm{AD}$, can have on the healthcare system and overall society. Proper management of AD has been shown to alleviate the work loss burden imposed by the disease, as shown by the results of clinical trials [25]. 
Table 2 Work productivity and healthcare resource use by Dermatology Life Quality Index severity band across EU5 countries

\begin{tabular}{|c|c|c|c|c|}
\hline & $\begin{array}{l}\text { Moderate effect } \\
\text { (DLQI 6-10) }\end{array}$ & $\begin{array}{l}\text { Very large effect } \\
\text { (DLQI 11-20) }\end{array}$ & $\begin{array}{l}\text { Extremely large effect } \\
\text { (DLQI 21-30) }\end{array}$ & $p$ value \\
\hline \multicolumn{5}{|l|}{ France } \\
\hline Number of patients & 157 & 82 & 17 & \\
\hline \multirow[t]{2}{*}{ Number employed } & 83 & 43 & 9 & \\
\hline & Mean (SD) & Mean (SD) & Mean (SD) & $p$ value \\
\hline Absenteeism \% (WPAI-GH) & $11.2(25.0)$ & $17.4(27.0)$ & $20.3(19.5)$ & 0.3146 \\
\hline Presenteeism \% (WPAI-GH) & $31.1(25.0)$ & $42.4(28.0)$ & $63.3(26.0)$ & 0.0008 \\
\hline Overall work impairment \% (WPAI-GH) & $33.6(27.7)$ & $47.9(31.0)$ & $69.0(27.8)$ & 0.0005 \\
\hline Healthcare provider visits & $7.85(8.00)$ & $8.11(10.11)$ & $9.76(7.81)$ & 0.6911 \\
\hline Emergency room visits & $0.50(1.29)$ & $0.73(1.77)$ & $1.88(2.71)$ & 0.0028 \\
\hline Hospitalizations & $0.27(0.59)$ & $0.41(0.92)$ & $0.65(1.41)$ & 0.0964 \\
\hline \multicolumn{5}{|l|}{ Germany } \\
\hline Number of patients & 98 & 68 & 17 & \\
\hline \multirow[t]{2}{*}{ Number employed } & 49 & 38 & 9 & \\
\hline & Mean (SD) & Mean (SD) & Mean (SD) & $p$ value \\
\hline Absenteeism \% (WPAI-GH) & $22.4(32.6)$ & $29.0(35.7)$ & $38.3(21.6)$ & 0.3517 \\
\hline Presenteeism \% (WPAI-GH) & $34.8(26.1)$ & $42.4(25.9)$ & $41.0(28.9)$ & 0.4239 \\
\hline Overall work impairment \% (WPAI-GH) & $40.4(30.2)$ & $52.1(28.9)$ & $64.4(27.7)$ & 0.0453 \\
\hline Healthcare provider visits & $11.62(9.75)$ & $11.34(11.15)$ & $13.47(12.75)$ & 0.7559 \\
\hline Emergency room visits & $0.28(0.74)$ & $0.34(0.66)$ & $0.88(1.32)$ & 0.014 \\
\hline Hospitalizations & $0.28(0.74)$ & $0.34(0.87)$ & $1.12(1.41)$ & 0.0013 \\
\hline \multicolumn{5}{|l|}{ Italy } \\
\hline Number of patients & 87 & 64 & 9 & \\
\hline \multirow[t]{2}{*}{ Number employed } & 56 & 43 & 8 & \\
\hline & Mean (SD) & Mean (SD) & Mean (SD) & $p$ value \\
\hline Absenteeism \% (WPAI-GH) & $14.2(25.7)$ & $14.0(19.7)$ & $17.6(19.2)$ & 0.9178 \\
\hline Presenteeism \% (WPAI-GH) & $39.6(26.6)$ & $43.3(25.6)$ & $70.0(12.0)$ & 0.0088 \\
\hline Overall work impairment \% (WPAI-GH) & $42.5(29.3)$ & $47.5(27.9)$ & $74.0(13.2)$ & 0.0141 \\
\hline Healthcare provider visits & $9.41(14.59)$ & $8.11(12.78)$ & $11.11(9.24)$ & 0.7536 \\
\hline Emergency room visits & $0.24(0.55)$ & $0.47(0.84)$ & $1.44(1.51)$ & $<.0001$ \\
\hline Hospitalizations & $0.08(0.27)$ & $0.19(0.50)$ & $0.78(1.09)$ & $<.0001$ \\
\hline
\end{tabular}


Table 2 continued

\begin{tabular}{|c|c|c|c|c|}
\hline & Mean $(S D)$ & Mean (SD) & Mean (SD) & $p$ value \\
\hline \multicolumn{5}{|l|}{ Spain } \\
\hline Number of patients & 78 & 51 & 3 & \\
\hline \multirow[t]{2}{*}{ Number employed } & 45 & 35 & 1 & \\
\hline & Mean (SD) & Mean (SD) & Mean (SD) & $p$ value \\
\hline Absenteeism \% (WPAI-GH) & $7.3(11.8)$ & $15.3(18.9)$ & $9.0(-)$ & 0.0746 \\
\hline Presenteeism \% (WPAI-GH) & $43.5(28.3)$ & $53.1(24.2)$ & $70.0(-)$ & 0.1972 \\
\hline Overall work impairment \% (WPAI-GH) & $47.3(28.9)$ & $58.9(26.2)$ & $72.0(-)$ & 0.1453 \\
\hline Healthcare provider visits & $7.08(5.95)$ & $9.75(7.22)$ & $9.00(6.00)$ & 0.0746 \\
\hline Emergency room visits & $0.65(1.07)$ & $1.39(1.42)$ & $0.33(0.58)$ & 0.0029 \\
\hline Hospitalizations & $0.09(0.51)$ & $0.47(0.86)$ & $0.00(0.00)$ & 0.0065 \\
\hline \multicolumn{5}{|l|}{ UK } \\
\hline Number of patients & 177 & 83 & 23 & \\
\hline \multirow[t]{2}{*}{ Number employed } & 86 & 51 & 18 & \\
\hline & Mean (SD) & Mean (SD) & Mean (SD) & $p$ value \\
\hline Absenteeism \% (WPAI-GH) & $10.9(25.4)$ & $14.9(26.3)$ & $23.9(25.2)$ & 0.1374 \\
\hline Presenteeism \% (WPAI-GH) & $29.5(26.2)$ & $28.5(28.0)$ & $60.6(25.1)$ & $<.0001$ \\
\hline Overall work impairment \% (WPAI-GH) & $32.3(28.6)$ & $33.2(31.5)$ & $67.9(21.2)$ & $<.0001$ \\
\hline Healthcare provider visits & $6.55(7.78)$ & $6.18(11.26)$ & $5.87(7.01)$ & 0.9118 \\
\hline Emergency room visits & $0.25(0.73)$ & $0.47(0.98)$ & $1.00(1.76)$ & 0.0009 \\
\hline Hospitalizations & $0.21(0.68)$ & $0.18(0.57)$ & $0.87(1.52)$ & 0.0003 \\
\hline
\end{tabular}

DLQI Dermatology Life Quality Index, EUS European Union 5, WPAI-GH Work Productivity and Activity Impairment-General Health questionnaire

This study also examined the prevalence of psychosocial comorbidities. Consistent with prior studies, we found that $>60 \%$ of patients experience some form of sleep difficulties [26]. However, our reported rates of anxiety (50\%) and depression $(75 \%$, with nearly $25 \%$ of all patients reporting moderately severe or severe depression) were higher than in prior studies $[27,28]$. The difference observed may be due to the population of the different studies. Many prior studies focused on the entire AD population rather than moderate-to-severe patients specifically, and these results would suggest that the psychological burden is greater among those with more severe disease.

The results of this study also suggest that the presence and increasing severity of these comorbidities are associated with poorer outcomes, particularly in health status, HRQoL, and work productivity loss. The effects of these comorbidities on healthcare resource use were less clear; in general, the more severe manifestations were associated with more healthcare provider visits and, in some cases, emergency 


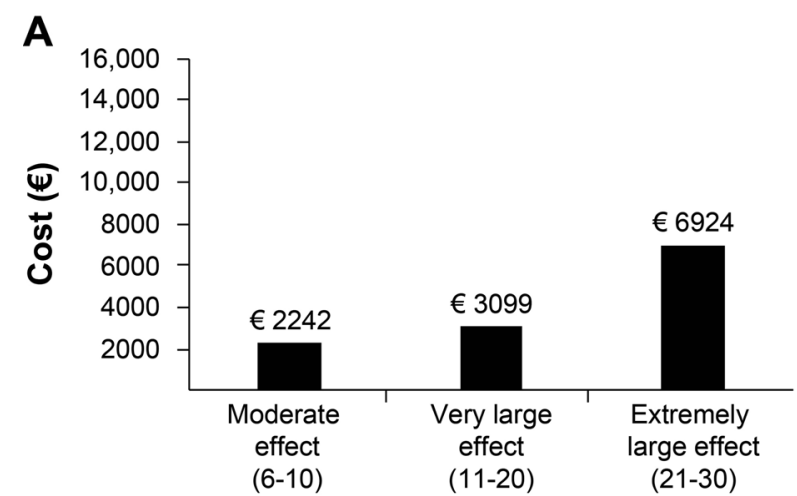

DLQI Severity Band Categories

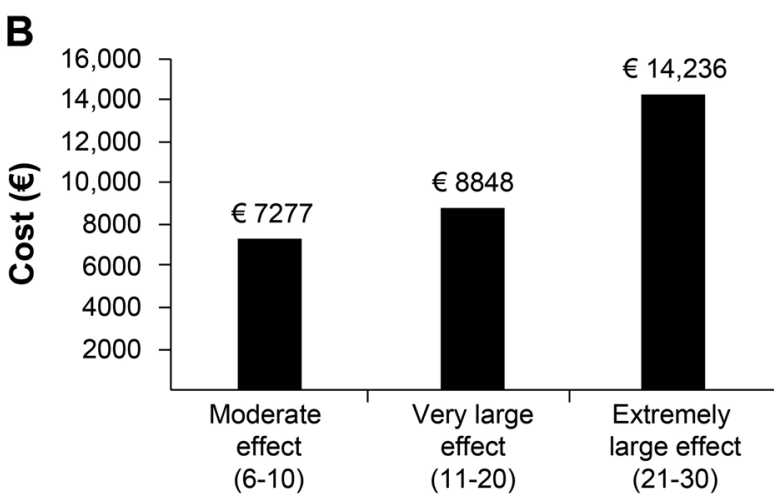

DLQI Severity Band Categories

Fig. 1 Annual per patient direct $(\mathbf{a})$ and indirect $(\mathbf{b})$ costs across the EU5 by DLQI severity bands. DLQI Dermatology Life Quality Index

Table 3 Prevalence of psychosocial comorbidities among moderate-to-severe atopic dermatitis patients across EU5 countries

\begin{tabular}{lllllll}
\hline $\boldsymbol{n}(\mathbf{\%})$ & $\begin{array}{l}\text { France } \\
(\boldsymbol{N}=\mathbf{2 5 6})\end{array}$ & $\begin{array}{l}\text { Germany } \\
(\boldsymbol{N}=\mathbf{1 8 3})\end{array}$ & $\begin{array}{l}\text { Italy } \\
(\boldsymbol{N}=\mathbf{1 6 0})\end{array}$ & $\begin{array}{l}\text { Spain } \\
(\boldsymbol{N}=\mathbf{1 3 2})\end{array}$ & $\begin{array}{l}\text { UK } \\
(\boldsymbol{N}=\mathbf{2 8 3})\end{array}$ & $\begin{array}{l}\text { Total EU5 } \\
(\boldsymbol{N}=\mathbf{1 0 1 4})\end{array}$ \\
\hline $\begin{array}{l}\text { Severity of sleep } \\
\text { difficulties }\end{array}$ & & & & & & \\
No sleep difficulties & $90(35.2)$ & $57(31.1)$ & $76(47.5)$ & $46(34.8)$ & $120(42.4)$ & $389(38.4)$ \\
Mild & $59(23.0)$ & $53(29.0)$ & $36(22.5)$ & $40(30.3)$ & $54(19.1)$ & $242(23.9)$ \\
Moderate & $73(28.5)$ & $55(30.1)$ & $40(25.0)$ & $33(25.0)$ & $85(30.0)$ & $286(28.2)$ \\
Severe & $34(13.3)$ & $18(9.8)$ & $8(5.0)$ & $13(9.8)$ & $24(8.5)$ & $97(9.6)$ \\
Anxiety & $147(57.4)$ & $54(29.5)$ & $82(51.3)$ & $77(58.3)$ & $174(61.5)$ & $534(52.7)$ \\
Depression (PHQ-9) & & & & & & \\
None-minimal & $69(27.0)$ & $35(19.1)$ & $40(25.0)$ & $33(25.0)$ & $68(24.0)$ & $245(24.2)$ \\
$\quad(0-4)$ & & & & & \\
Mild (5-9) & $91(35.5)$ & $58(31.7)$ & $65(40.6)$ & $39(29.5)$ & $71(25.1)$ & $324(32.0)$ \\
$\begin{array}{l}\text { Moderate (10-14) } \\
\text { Moderately severe }\end{array}$ & $35(17.6)$ & $48(26.2)$ & $33(20.6)$ & $24(18.2)$ & $54(19.1)$ & $204(20.1)$ \\
$\quad(15-19)$ & $27(14.8)$ & $17(10.6)$ & $25(18.9)$ & $47(16.6)$ & $149(14.7)$ \\
Severe (20-27) & $18(7.0)$ & $15(8.2)$ & $5(3.1)$ & $11(8.3)$ & $43(15.2)$ & $92(9.1)$ \\
\hline
\end{tabular}

EUS European Union 5; PHQ-9 Patient Health Questionnaire-9

room visits and hospitalizations. However, these differences were not always statistically significant. This suggests these comorbidities predominantly exacerbate the HRQoL and indirect cost burden rather than the direct cost burden.

Our findings suggest a large incremental burden for patients with psychosocial 


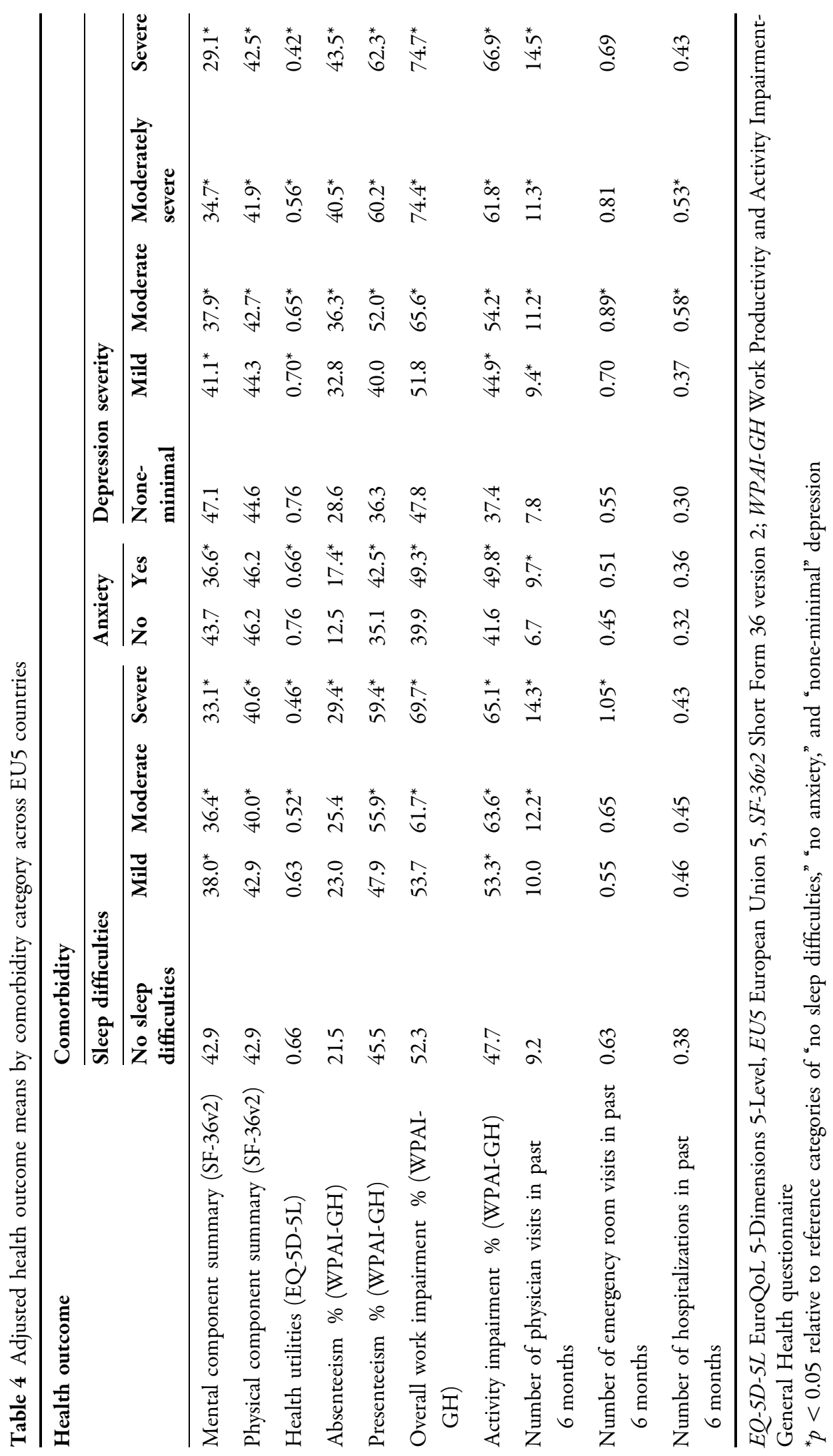


comorbidities. Prior studies have demonstrated that these comorbidities are more frequent among patients with less controlled disease [4] and that effective AD therapies can reduce the levels of anxiety, depression, and sleep disturbances [29]. Our study's results suggest that improved management of the psychosocial health of patients can have additional benefits for the healthcare system and society.

\section{Limitations}

The NHWS database consists solely of patientreported information, without any verification (clinician or otherwise) of responses. Although self-report of $\mathrm{AD}$ has been found to be reliable [30], defining severity based on DLQI bands may not produce the same results as using treatment history, Eczema Area and Severity Index score, and/or percentage of body surface area affected, none of which were available in the database. The cost data were estimated using patient-reported information rather than medical claims, although it did align with published data using other methods. It should be noted that indirect costs included only work loss and direct costs included only physician visits, emergency room visits, and hospitalizations. Costs associated with other aspects of disease management were not included. Because of the cross-sectional nature of the data, any relationships uncovered in the study can only be viewed as associations because the presence and direction of causality cannot be known. Although the study relied upon multivariable models to rule out alternative explanations, it is possible other factors could explain the relationships observed here. Finally, the current sample was recruited from the NHWS, and although the broad demographic characteristics of the entire NHWS sample and those of each respective country were similar, the extent to which our specific AD sample is generalizable to the broader $\mathrm{AD}$ population is unclear.

\section{CONCLUSIONS}

Moderate-to-severe $\mathrm{AD}$ results in a significant indirect and direct cost burden across the EU5.
Psychosocial comorbidities (i.e., sleep difficulties, depression, and anxiety) were common, observed in more than half of moderate-tosevere AD patients, and significantly associated with decrements in HRQoL and significantly associated with work-related impairment. Reducing the burden of these psychosocial comorbidities in $\mathrm{AD}$ could have significant benefit for patients and society.

\section{ACKNOWLEDGMENTS}

Funding. This study and the journal's Rapid Service Fee were sponsored by Pfizer Inc.

Medical Writing, Editorial, and Other Assistance. Medical writing support under the guidance of the authors was provided by Juan Sanchez-Cortes, PhD, at ApotheCom, San Francisco, CA, and was sponsored by Pfizer Inc., New York, NY, in accordance with Good Publication Practice (GPP3) guidelines (Ann Intern Med. 2015;163:461-464).

Authorship. All named authors meet the International Committee of Medical Journal Editors (ICMJE) criteria for authorship for this article, take responsibility for the integrity of the work as a whole, and have given their approval for this version to be published.

Disclosures. Giampiero Girolomoni has been principal investigator in clinical trials sponsored by and/or has received personal fees from Pfizer Inc., AbbVie, Abiogen Pharma, Almirall, Amgen, Biogen, Boehringer Ingelheim, Bristol-Myers Squibb, Celgene, Celltrion Healthcare, Eli Lilly, LEO Pharma, Menlo Therapeutics, Novartis, Regeneron, Samsung, Sandoz, Sanofi Genzyme, and UCB. Thomas Luger has participated in advisory boards for Pfizer Inc., AbbVie, Amgen, Argenx, Celgene, Ceres Pharma, Eli Lilly, Galderma, Janssen, La RochePosay, LEO Pharma, Menlo Therapeutics, Mylan/Meda, Novartis, Pierre Fabre, PIQUR Therapeutics, Sandoz, Sanofi, and Symrise; acted as an investigator for Pfizer Inc., AbbVie, Celgene, Eli Lilly, Janssen, LEO Pharma, Menlo 
Therapeutics, Novartis, and Sandoz; participated as a speaker for Pfizer Inc., AbbVie, Galderma, Janssen, La Roche-Posay, Merck Sharp \& Dohme, Mylan, Novartis, and Sanofi; and received funding from Pfizer Inc., AbbVie, Celgene, Jansen-Cilag, Merck Sharp \& Dohme, Mylan/Meda, Novartis, and Wolfe Laboratories. Audrey Nosbaum is an investigator for AbbVie, Eli Lilly, Incyte, LEO Pharma, Novartis, and Sanofi; a consultant for Pfizer Inc., AbbVie, Eli Lilly, Galderma, LEO Pharma, Novartis, and Sanofi; a speaker for AbbVie, Regeneron, and Sanofi; and on advisory boards for Pfizer Inc., AbbVie, LEO Pharma, and Sanofi. David Gruben, William Romero, Lyndon John Llamado, and Marco DiBonaventura are employees and stockholders of Pfizer Inc.

Compliance with Ethics Guidelines. The protocol and study materials associated with the original fielding of the 2017 NHWS was reviewed by the Pearl Institutional Review Board (Indianapolis, IN) and granted exemption status.

Data Availability. The datasets generated during and/or analyzed during the current study are not publicly available due to a data use agreement between the National Health and Wellness Survey and the authors but are available from the National Health and Wellness Survey on reasonable request.

Open Access. This article is licensed under a Creative Commons Attribution-NonCommercial 4.0 International License, which permits any non-commercial use, sharing, adaptation, distribution and reproduction in any medium or format, as long as you give appropriate credit to the original author(s) and the source, provide a link to the Creative Commons licence, and indicate if changes were made. The images or other third party material in this article are included in the article's Creative Commons licence, unless indicated otherwise in a credit line to the material. If material is not included in the article's Creative Commons licence and your intended use is not permitted by statutory regulation or exceeds the permitted use, you will need to obtain permission directly from the copyright holder. To view a copy of this licence, visit http://creativecommons.org/licenses/by$\mathrm{nc} / 4.0 /$.

\section{REFERENCES}

1. Boguniewicz M, Fonacier L, Guttman-Yassky E, Ong PY, Silverberg J, Farrar JR. Atopic dermatitis yardstick: practical recommendations for an evolving therapeutic landscape. Ann Allergy Asthma Immunol. 2018;120(10-22):e12.

2. DaVeiga SP. Epidemiology of atopic dermatitis: a review. Allergy Asthma Proc. 2012;33:227-34.

3. Eckert L, Gupta S, Amand C, Gadkari A, Mahajan P, Gelfand JM. Impact of atopic dermatitis on healthrelated quality of life and productivity in adults in the United States: an analysis using the National Health and Wellness Survey. J Am Acad Dermatol. 2017;77(274-279):e273.

4. Simpson EL, Guttman-Yassky E, Margolis DJ, et al. Association of inadequately controlled disease and disease severity with patient-reported disease burden in adults with atopic dermatitis. JAMA Dermatol. 2018;154:903-12.

5. Drucker AM, Qureshi AA, Amand C, et al. Health care resource utilization and costs among adults with atopic dermatitis in the United States: a claims-based analysis. J Allergy Clin Immunol Pract. 2018;6:1342-8.

6. Shrestha S, Miao R, Wang L, Chao J, Yuce H, Wei W. Burden of atopic dermatitis in the United States: analysis of healthcare claims data in the commercial, Medicare, and Medi-Cal databases. Adv Ther. 2017;34:1989-2006.

7. Sicras-Mainar A, Navarro-Artieda R, Carrascosa Carrillo JM. Economic impact of atopic dermatitis in adults: a population-based study (IDEA Study). Actas Dermosifiliogr. 2018;109:35-46.

8. Ariëns LFM, van Nimwegen KJM, Shams M, et al. Economic burden of adult patients with moderate to severe atopic dermatitis indicated for systemic treatment. Acta Derm Venereol. 2019;99:762-8.

9. Yu SH, Attarian H, Zee P, Silverberg JI. Burden of sleep and fatigue in US adults with atopic dermatitis. Dermatitis. 2016;27:50-8.

10. Ronnstad ATM, Halling-Overgaard AS, Hamann CR, Skov L, Egeberg A, Thyssen JP. Association of atopic dermatitis with depression, anxiety, and suicidal ideation in children and adults: a systematic review 
and meta-analysis. J Am Acad Dermatol. 2018;79(448-456):e430.

11. Sandhu JK, Wu KK, Bui TL, Armstrong AW. Association between atopic dermatitis and suicidality: a systematic review and meta-analysis. JAMA Dermatol. 2019;155:178-87.

12. Yu SH, Silverberg JI. Association between atopic dermatitis and depression in US adults. J Invest Dermatol. 2015;135:3183-6.

13. United States Census Bureau. International Data Base. https://www.census.gov/data-tools/demo/ idb/informationGateway.php. Accessed 7 May 2020 .

14. Finlay AY, Khan GK. Dermatology Life Quality Index (DLQI) - a simple practical measure for routine clinical use. Clin Exp Dermatol. 1994;19: 210-6.

15. Quan H, Li B, Couris CM, et al. Updating and validating the Charlson comorbidity index and score for risk adjustment in hospital discharge abstracts using data from 6 countries. Am J Epidemiol. 2011;173:676-82.

16. Kroenke K, Spitzer RL, Williams JB. The PHQ-9: validity of a brief depression severity measure. J Gen Intern Med. 2001;16:606-13.

17. Ware JJ, Kosinski M, Bjorner J, Turner-Bowker D, Gandek B, Meruish M. User's manual for the SF36v2 health survey. Lincoln: Quality Metric Inc; 2007.

18. Herdman M, Gudex C, Lloyd A, et al. Development and preliminary testing of the new five-level version of EQ-5D (EQ-5D-5L). Qual Life Res. 2011;20: 1727-36.

19. Reilly MC, Zbrozek AS, Dukes EM. The validity and reproducibility of a work productivity and activity impairment instrument. Pharmacoeconomics. 1993;4:353-65.

20. Eurostat. Annual net earnings. http://appsso. eurostat.ec.europa.eu/nui/show.do?dataset=earn nt_net\&lang=en. Accessed May 7, 2020.
21. Bloudek LM, Stokes M, Buse DC, et al. Cost of healthcare for patients with migraine in five European countries: results from the International Burden of Migraine Study (IBMS). J Headache Pain. 2012;13:361-78.

22. Eurostat. Harmonised indices of consumer prices inflation rate. https://ec.europa.eu/eurostat/tgm/ table.do?tab=table\&init $=1 \&$ language $=e n \& p c o d e=$ tec00118\&plugin=1. Accessed 7 May 2020.

23. Eurostat. Hospital discharges and length of stay for inpatient and curative care. http://appsso.eurostat. ec.europa.eu/nui/show.do?dataset=hlth_co_ dischls\&lang=en. Accessed 7 May 2020.

24. Murota H, Inoue S, Yoshida K, Ishimoto A. Cost of illness study for adult atopic dermatitis in Japan: A cross-sectional Web-based survey. J Dermatol. 2020. https://doi.org/10.1111/1346-8138.15366.

25. Mihara R, Kabashima K, Furue M, Nakano M, Ruzicka T. Nemolizumab in moderate to severe atopic dermatitis: an exploratory analysis of work productivity and activity impairment in a randomized phase II study. J Dermatol. 2019;46:662-71.

26. Jeon C, Yan D, Nakamura M, et al. Frequency and management of sleep disturbance in adults with atopic dermatitis: a systematic review. Dermatol Ther (Heidelberg). 2017;7:349-64.

27. Cheng BT, Silverberg JI. Depression and psychological distress in US adults with atopic dermatitis. Ann Allergy Asthma Immunol. 2019;123:179-85.

28. Silverberg JI, Gelfand JM, Margolis DJ, et al. Symptoms and diagnosis of anxiety and depression in atopic dermatitis in U.S. adults. Br J Dermatol. 2019;181:554-65.

29. Simpson EL, Bieber T, Guttman-Yassky E, SOLO 1 and SOLO 2 Investigators, et al. Two phase 3 trials of dupilumab versus placebo in atopic dermatitis. N Engl J Med. 2016;375:2335-48.

30. Silverberg JI, Patel N, Immaneni S, et al. Assessment of atopic dermatitis using self-report and caregiver report: a multicentre validation study. $\mathrm{Br} \mathrm{J}$ Dermatol. $2015 ; 173: 1400-4$. 